\title{
C-reactive protein concentration in bipolar disorder: association with genetic variants
}

\author{
Ann-Kristin Evers ${ }^{1}$, Julia Veeh ${ }^{1}$, Rhiannon McNeill ${ }^{1,2}$, Andreas Reif ${ }^{1+}$ and Sarah Kittel-Schneider ${ }^{1,2^{*}+}$ (D)
}

\begin{abstract}
Background: Several recent studies have investigated the role of C-reactive protein (CRP) in bipolar disorder (BD), but few studies have directly investigated the interaction between CRP genetic variants and peripheral CRP concentration across different phases of BD. In this study, we aimed to replicate previous findings that demonstrated altered $\mathrm{CRP}$ levels in $\mathrm{BD}$, and to investigate whether there is an association of peripheral protein expression with genetic variants in the CRP gene.

Methods: 221 patients were included in the study, of which 183 (all episodes, 46 not medicated, 174 medicated) were genotyped for CRP single-nucleotide polymorphisms (SNPs) shown to influence peripheral CRP protein expression (rs1800947, rs2808630, rs1417938, rs1205).

Results: There were no differences in CRP levels associated with the genotypes, only regarding the rs 1205 SNP there were significantly different CRP protein expression between the genotypes when taking body mass index, age, BD polarity, subtype and leukocyte number into account. However, we could show significantly elevated CRP protein expression in manic patients compared to euthymic and depressed patients, independent from genotype. Medication was found to have no effect on CRP protein expression.
\end{abstract}

Conclusions: These results indicate that low grade inflammation might play a role in mania and might be rather a state than a trait marker of bipolar disorder.

Keywords: Bipolar disorder, Genotype, C-reactive protein, Biomarker, Inflammation

\section{Background}

Bipolar disorder (BD) is primarily a periodic disease that has a global burden (Ferrari et al. 2016). It is characterized by the occurrence of (hypo-)manic and depressive episodes, and in a number of patients these mood states increase in frequency and severity over time, as well as decreasing responsiveness to treatment and that can result in a chronic course (Gildengers et al. 2014). The pathogenesis of $\mathrm{BD}$ is still relatively unknown. According to current findings, it is a multifactorial disease (Pitchot et al. 2012). BD is among the psychiatric disorders with the highest heritability, which is estimated at about $80 \%$

\footnotetext{
*Correspondence: kittel_s@ukw.de

${ }^{\dagger}$ Andreas Reif and Sarah Kittel-Schneider contributed equally to this work

2 Department of Psychiatry, Psychosomatic Medicine and Psychotherapy, University Hospital, University of Würzburg, Margarete-Höppel-Platz 1, 97080 Würzburg, Germany

Full list of author information is available at the end of the article
}

(Craddock and Jones 1999). However, developmental and environmental risk factors are additionally thought to play a role in the pathogenesis of the disorder (Landgraf et al. 2014).

There is increasing evidence that neuro-inflammation may play a role in the molecular pathomechanisms of BD (Muneer 2016). Increased levels of the inflammatory marker $\mathrm{C}$-reactive protein (CRP) have been reported in $\mathrm{BD}$ in comparison to healthy controls (Bai et al. 2014; Chang and Chen 2017; Dargél et al. 2015). Elevated CRP levels have also been associated with an increased level of all-cause mortality in BD (Hayes et al. 2015). BD has been linked to metabolic and immunologic dysregulations (Berk et al. 2013; Leboyer et al. 2016; Modabbernia et al. 2013; Munkholm et al. 2013), and in BD patients, there appears to be a high comorbidity with somatic diseases such as cardiovascular disease, diabetes mellitus and autoimmune thyroiditis (Benros et al. 2013; Chakrabarti 
2011; Rosenblat et al. 2017). In support of this, mortality due to cardiovascular disease has been reported as doubled in BD patients (Osby et al. 2001). Taken together, it has therefore been suggested that there are inflammatory subgroups in $\mathrm{BD}$, and possibly also in other psychiatric disorders (Osimo et al. 2018). This would place these types of mood disorder in an inflammatory disease cluster, together with e.g. cardiovascular disease and obesity, in a "diseasesome" network (Midic et al. 2009; Perrino et al. 2017). Delineating this cluster, for example with the help of biomarkers, might pinpoint a group of patients which could be responsive to treatment options targeting the inflammasome.

The potential role and the direction of causality of CRP in the pathogenesis of BD is currently unclear. It has been hypothesized that stress can trigger an increase in CRP expression, which in turn leads to increased permeability of the blood-brain barrier. This consequently permits easier diffusion across the barrier for certain molecules, such as pro-inflammatory cytokines or auto-antibodies, which could cause multiple abnormalities in the brain (Hsuchou et al. 2012). CRP levels may act as a mood state marker in BD (Dargél et al. 2015; Jacoby et al. 2016; Wysokinski et al. 2015), and high levels of CRP may also represent an early warning sign for the onset of manic symptoms in depressed patients (Becking et al. 2013). Studies in the general population suggest that elevated CRP levels may even be predictive for the onset of BD (Wium-Andersen et al. 2016), and high levels of CRP are significantly correlated with BD disease severity (Dickerson et al. 2007; Lee et al. 2013). However, there are also negative findings regarding an association of CRP and $\mathrm{BD}$, which may be partly due to the immunosuppressive actions of mood stabilizing medication (Dickerson et al. 2015; Haarman et al. 2014). Furthermore, it is not known what may trigger CRP production in BD patients. External stressors might activate the hypothalamus-pituitary-adrenal (HPA) axis, leading to increased secretion of cortisol and adrenergic hormones and an according change in immunological processes. However as elevated CRP levels are only found in a subgroup of BD patients, genetic susceptibility might pay a role. In support of this, several genetic polymorphisms in the CRP and other genes have been shown to influence peripheral CRP levels in different cohorts of psychiatric and non-psychiatric patients, as well as the general population (Carlson et al. 2005; Halder et al. 2010; Pankow et al. 2001; Prins et al. 2016; Reiner et al. 2012).

The first aim of the present cross-sectional study was to determine whether CRP genotype influences peripheral CRP concentration in BD patients. Patients were genotyped for the previously published functional $C R P$ single nucleotide polymorphisms (SNPs) rs1800947 (Halder et al. 2010), rs1417938 (Henderson et al. 2015; MartínezCalatrava et al. 2007), rs1205 (Halder et al. 2010; FloresAlfaro et al. 2012) and rs2808630 (Kittel-Schneider et al. 2018). We then investigated a possible association of current polarity, bipolar subtype, medication and several other variables with serum CRP concentration.

\section{Methods \\ Participants}

A naturalistic sample of 221 BD patients in all mood phases (depressed, manic, mixed, euthymic) were recruited from 2009 to 2014 who were treated as inpatients at the Department of Psychiatry, Psychosomatic Medicine and Psychotherapy, University Hospital Würzburg, Würzburg, Germany. The patients were all of Caucasian origin and mostly from the lower Franconian area. The patients were diagnosed according to DSM-IV criteria independently by two specialists (SKS and AR). Information about smoking status, BMI, medication, CRP values, renal function and leukocyte values was obtained from the clinical routine data during the inpatient treatment. Blood for CRP analysis was drawn of the majority of the patients when the patients were admitted, only in few cases (the euthymic cases) blood was taken for CRP levels when the patients were discharged. A detailed description of sample characteristics and demographic data is presented in Table 1. Inclusion criteria were a diagnosis of bipolar disorder as primary psychiatric diagnosis and age $\geq 18$ years. Exclusion criteria were severe somatic disorders (severe cardiovascular disease, severe neurological diseases, acute or chronic infections, carcinomas and autoimmune diseases) and organic affective disorders. Written informed consent was obtained from all participants before study evaluation. The authors assert that all procedures contributing to this work comply with the ethical standards of the relevant national and institutional committees on human experimentation and with the Helsinki Declaration of 1975, as revised in 2008. The ethics committee of the University of Würzburg approved the study.

\section{Genotyping}

183/221 participants gave approval for genetic testing. DNA was isolated from ethylenediaminetetraacetic acid (EDTA)-monovettes using the de-salting method (Miller et al. 1988) and DNA concentration and quality was assessed by spectrophotometric measurement (Infinite ${ }^{\circledR} 200$ PRO, Tecan Group Ltd., Männedorf, Switzerland). Competitive Allele Specific Polymerase Chain Reaction (KASP) assay (He et al. 2014) was performed according to manufacturer's instructions (LGC Genomics, Berlin, Germany) to genotype previously published SNPs in the CRP gene (rs1800947, rs1417938, rs1205 
Table 1 Sample characteristics and demographic data of bipolar patients

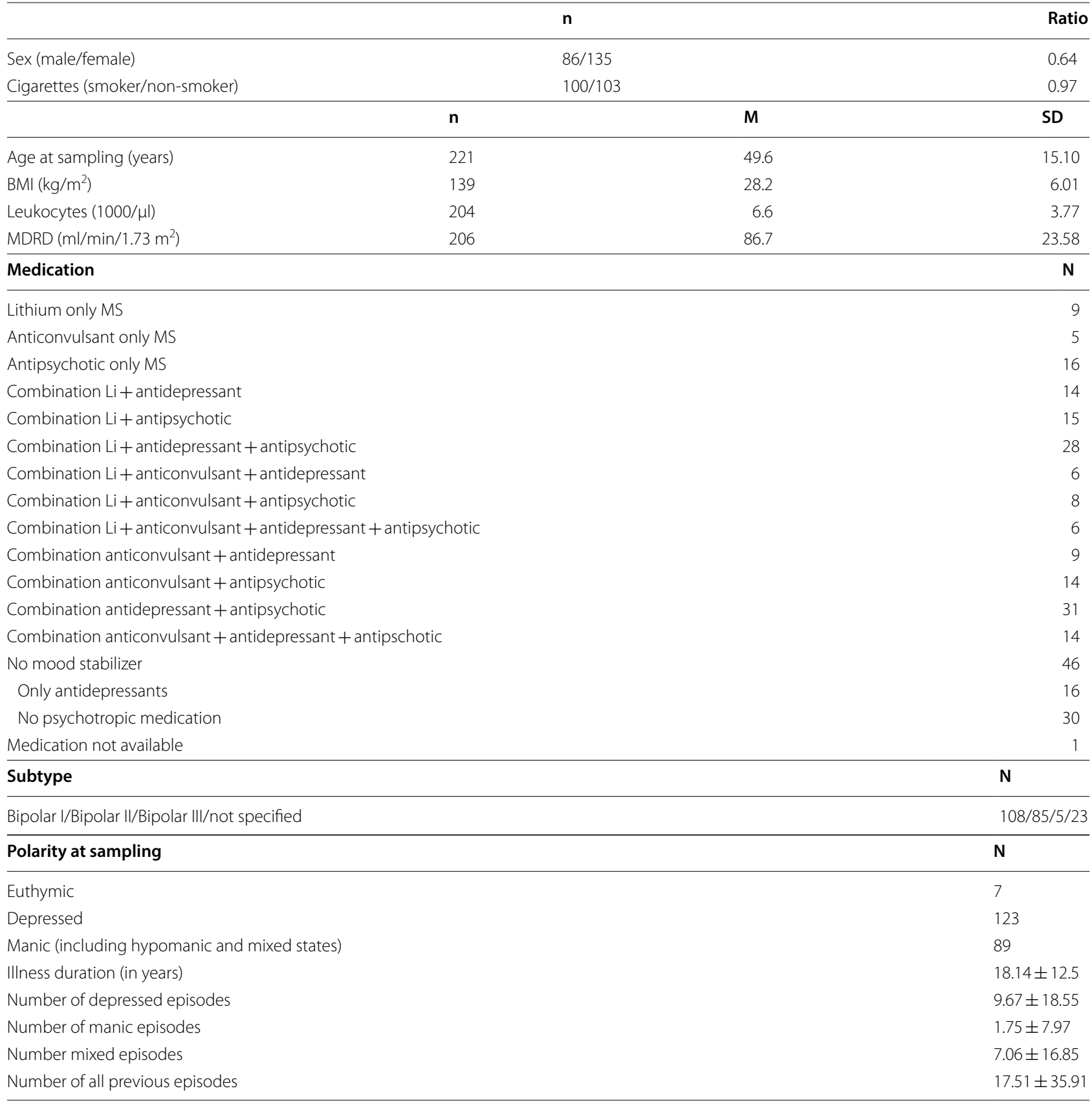

$B M I$ body mass index, MDRD Modification of Diet in Renal Disease, MS mood stabilizer, Li lithium

and one tagSNP rs2808630). The SNPs were selected due to previously published studies in different study population which showed that those common variants might influence the CRP protein levels [rs1800947 (Halder et al. 2010), rs1417938 (Henderson et al. 2015; Martínez-Calatrava et al. 2007), rs1205 (Halder et al. 2010; Flores-Alfaro et al. 2012) and rs2808630 (KittelSchneider et al. 2018)].
5 to $50 \mathrm{ng} / \mu \mathrm{l}$ of DNA was tested in a 384-well plate by Wet DNA method. Fluorescent signal from the two FRET (fluorescence resonance energy transfer) cassettes [frequency-and amplitude modulation (FAM) and hexachlorocyclopentadiene (HEX)] was detected with a LightCycler ${ }^{\circledR} 480$ (F. Hoffmann-La Roche Ltd., Basel, Switzerland). In order to confirm the genotyping quality, we analyzed samples in duplicates as internal controls 
on each plate, including negative water controls. As an external control, two additional samples whose genotypes were already known were also included on each plate, confirming the genotyping quality over all measurements. Genotype frequencies of all tested CRP SNPs were consistent with the Hardy-Weinberg equilibrium. Recently, rs17460165, rs17860481 and rs52802864 SNPs have been merged into one SNP, rs1800947. However, C and $\mathrm{G}$ alleles are the most common alleles in the European population, therefore it did not appear necessary to genotype for other newly described alleles (see http://www.ensembl.org/Homo_sapiens/Variation/ Sequence $\mathrm{db}=$ core $; \mathrm{r}=1: 159713148-159714148 ; \mathrm{v}=\mathrm{rs} 180$ $0947 ; \mathrm{vdb}=$ variation; $\mathrm{vf}=1229971)$.

\section{CRP serum levels}

CRP serum levels were measured in routine blood parameter checks when patients were hospitalized. Serum CRP was measured with the cobas ${ }^{\circledR}$ system (cobas ${ }^{\circledR}$ Integra 800 , cobas ${ }^{\circledR} 6000$, cobas ${ }^{\circledR} 8000$, Roche Diagnostics, Indianapolis, USA) according to manufacturer's instructions. This system measures human CRP by agglutination with latex particles which are coated with anti-CRP-antibodies. The amount of agglutination is then measured by turbidimetry at $552 \mathrm{~nm}$. The normal range of CRP with this method is given between 0.0 and $0.5 \mathrm{mg} / \mathrm{dl}$.

\section{Statistical analysis}

Statistical analyses were conducted with SPSS (Statistical Package for the Social Sciences for Windows, version 24, IBM Corp., Armonk, New York). CRP levels were not normally distributed, as revealed by testing with the Kolmogorov-Smirnov and Shapiro-Wilk tests (both $\mathrm{p}<0.001$ ). Therefore non-parametric tests were conducted to determine whether genotype differences could be seen in CRP expression (Kruskal-Wallis test, Mann-Whitney U-test). When the number of patients was large enough in the subgroup analysis, for example regarding the episodes, ANOVA and ANCOVA were also performed. For those SNPs whose subgroups were large enough, we additionally conducted exploratory ANOVA and ANCOVA analysis including several covariates. Correlation of CRP with metric variables was tested by Spearman's test. The level of significance was corrected for multiple comparison with Bonferroni correction (4 tested SNPs for the main hypothesis, $\mathrm{p} \leq 0.05 / 4$ ) and set at $\mathrm{p} \leq 0.013$.

\section{Results}

\section{Association of confounders with CRP levels}

CRP serum levels in the whole sample were significantly positively correlated with body mass index (Spearman's correlation $r=0.359, p<0.0001$ ), age (Spearman' s correlation $r=0.186, p=0.005)$ and leukocyte numbers (Spearman's correlation, $r=0.253, p<0.0001$ ). Renal function as measured by Modification of Diet in Renal Disease (MDRD) value were not significantly correlated with CRP levels. Even though nominally increased CRP values were observed in male patients $(n=86$, $M=0.4280 \mathrm{mg} / \mathrm{dl}, S D$ 0.90729) compared to female patients ( $n=135, M=0.3805 \mathrm{mg} / \mathrm{dl}, S D 0.05137)$, the difference was not statistically significant $[t(219)=-0.470$, $p=0.639$ ]. The same applies to the nominally increased CRP for smokers $(n=100, M=0.446 \mathrm{mg} / \mathrm{dl}, S D 0.85207)$ compared to non-smokers $(n=103, M=0.3670 \mathrm{mg} / \mathrm{dl}$, $S D$ 0.65085). CRP levels were not significantly different between patients taking lithium and patients taking other medication (lithium group $\mathrm{n}=86$ vs. non-lithium group $\mathrm{n}=135$, Mann-Whitney-U-test, $p=0.512$ ).

The BD group as a whole had a mean CRP concentration of $0.40 \mathrm{ml} / \mathrm{d} l$ ( $\pm 0.73 \mathrm{mg} / \mathrm{dl} \mathrm{SD;} 95 \%$ CI 0.30 to 0.50 ), with significantly elevated CRP levels during manic episodes after correction for multiple comparison [ANOVA, $F(2,216)=5.888, p=0.003$ ] (see Fig. 1) compared to euthymic and depressed episodes. Manic patients had a mean CRP level concentration of $0.60 \mathrm{mg} / \mathrm{dl}( \pm 1.05 \mathrm{mg} /$ dl $S D$, with a range between $0.01 \mathrm{mg} / \mathrm{dl}$ and $5.90 \mathrm{mg} /$ $\mathrm{dl})$, while euthymic patients had a mean concentration of $0.20 \mathrm{mg} / \mathrm{dl}( \pm 0.22 \mathrm{mg} / \mathrm{dl} S D$, with a range between $0.03 \mathrm{mg} / \mathrm{dl}$ and $0.68 \mathrm{mg} / \mathrm{dl}$ ) and depressed patients had a mean concentration of $0.27 \mathrm{mg} / \mathrm{dl}( \pm 0.34 \mathrm{mg} / \mathrm{dl} S D$, with a range between $0.01 \mathrm{mg} / \mathrm{dl}$ and $1.99 \mathrm{mg} / \mathrm{dl}$ ) (see Fig. 1). Significant differences were additionally found relating to the subtypes of BD. Patients classified as bipolar subtype I ( $n=108, M=0.5340 \mathrm{mg} / \mathrm{dl}, S D 0.07176)$ had significantly elevated CRP levels $[t(139,792)=2.717, p=0.007]$ in

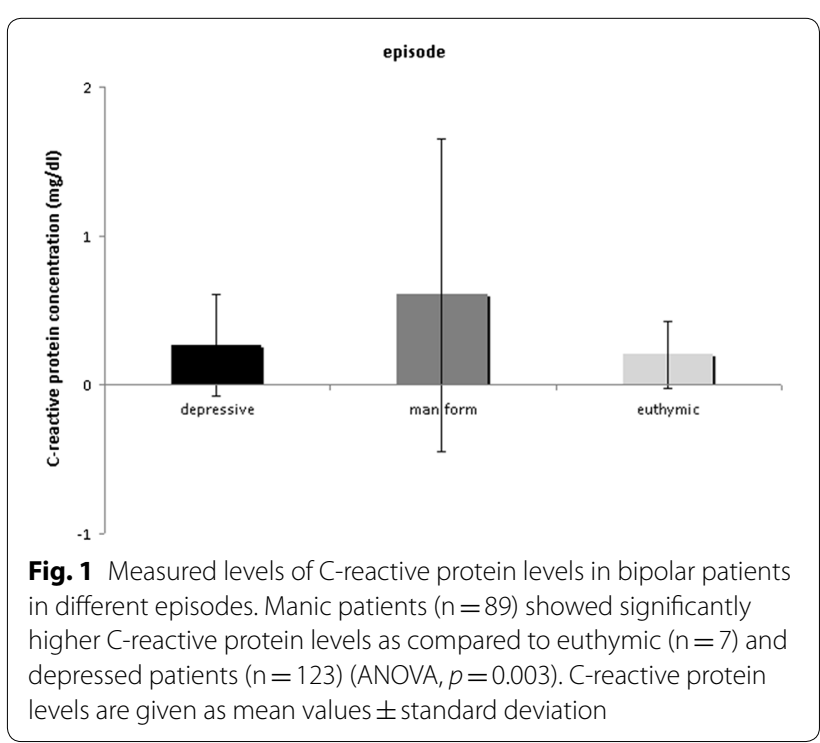


comparison to bipolar subtype II $(n=85, M=0.2601 \mathrm{mg}$ / dl, SD 0.34693), BD III and BD NOS. However, because there were significantly more manic episode patients in the BD I group (Chi-Square test, $p=0.005$ ), an exploratory ANCOVA was calculated including episode as a covariate. The result was then no longer significant after correction for multiple comparison (ANCOVA, CRP concentration differences between BD I, BD II, BD III and BD NOS, $p=0.032$ ). Duration of illness was significantly positively correlated with CRP levels (Spearman's correlation $r=0.212, p=0.004$ ).

\section{Association of genetic variation in the CRP gene with serum CRP concentration}

We assessed if there were differences between the genotypes of four SNPs (rs1800947, rs1417938, rs1205 and rs2808630) in CRP levels (Table 2). No significant differences in CRP levels were detected between different genotypes using non parametric Kruskal-Wallis analysis. However, exploratory ANCOVA analysis using body mass index, leukocyte number, age, current polarity and bipolar subtype as covariables revealed significant differences between the genotypes in the rs1205 SNP, which remained marginally significant even after correcting for multiple comparison [ANCOVA, $F(2,710)=1.023$, $p=0.013]$. No significant differences were found for any of the other SNPs. However, there was a trend for increased CRP expression in the minor AA carriers of the rs1417938 SNP, for decreased CRP levels in the minor allele carriers of rs 2808630 and rs 1800947 SNPs (Table 2). The distribution of all genotypes, call rates and minor allel frequency is given in Additional file 1: Table S1.
Additionally, we evaluated if there was a different distribution of the genotypes between the different current episodes, which was not the case (Chi Square-test, every $p \geq 0.5$, see Additional file 2: Table S2a-d).

\section{Discussion}

We were able to replicate previous findings of increased CRP levels in BD patients suffering from a manic episode as compared to euthymic and depressed patients (Horsdal et al. 2017; Wysokinski et al. 2015). This finding is also supported by a previous meta-analysis (Fernandes et al. 2016). However, inconsistent findings have been reported, finding either no CRP level differences between episodes or also elevated CRP levels between in depressed vs. euthymic patients (Balukova et al. 2016; Jacoby et al. 2016; Tsai et al. 2014). Furthermore, a previous meta-analysis has shown significantly elevated CRP levels in manic but also in euthymic patients compared to depressed patients with BD (Dargél et al. 2015). Taken together, those results point to an inflammatory component in BD and the results of our own and previous studies suggest that elevated CRP levels might rather be a state than a trait marker of BD (Dargél et al. 2015). However, it has to be considered, that most studies are investigating medicated patients and medication might have an effect on CRP concentration. But it has been published that increased CRP levels could be measured during the manic episode of BD I patients, in this sample only in medication-free patients (Uyanik et al. 2015). Even though the anti-inflammatory effects of lithium could be demonstrated in earlier studies (Beurel and Jope 2014; Fond et al. 2014), lithium (among other drugs) did not have a significant effect on CRP concentration in our

Table 2 Genotype distribution and C-reactive protein concentration in bipolar patients

\begin{tabular}{|c|c|c|c|}
\hline rs1800947 & GG & CG & CC \\
\hline$n$ & 140 & 17 & 2 \\
\hline CRP $[\mathrm{mg} / \mathrm{dl}]$ & $0.39 \pm 0.73 \mathrm{SD}$ & $0.19 \pm 0.23 \mathrm{SD}$ & $0.25 \pm 0.10 S D$ \\
\hline rs1417938 & TT & AT & AA \\
\hline$n$ & 89 & 75 & 15 \\
\hline CRP $[\mathrm{mg} / \mathrm{dl}]$ & $0.42 \pm 0.88 \mathrm{SD}$ & $0.36 \pm 0.52 S D$ & $0.32 \pm 0.27 \mathrm{SD}$ \\
\hline rs1205 & $\mathrm{CC}$ & CT & TT \\
\hline$n$ & 87 & 69 & 25 \\
\hline CRP $[\mathrm{mg} / \mathrm{dl}]$ & $0.41 \pm 0.71 \mathrm{SD}$ & $0.32 \pm 0.44 S D$ & $0.43 \pm 1.18 \mathrm{SD}$ \\
\hline rs2808630 & TT & CT & $\mathrm{CC}$ \\
\hline$n$ & 83 & 80 & 10 \\
\hline CRP [mg/dl] & $0.37 \pm 0.71 S D$ & $0.35 \pm 0.54 S D$ & $0.82 \pm 1.55 \mathrm{SD}$ \\
\hline
\end{tabular}

Genotype distribution of the 4 investigated SNPs in the whole sample is displayed as well as mean CRP concentration \pm SD

CRP C-reactive protein, $n$ number, $S D$ standard deviation 
study which is consistent with a previous meta-analysis (Dargél et al. 2015).

As already shown, we also found an association between CRP level and body mass index (Bai et al. 2015; Marshe et al. 2017), and between CRP levels and patient's age (Avramopoulos et al. 2015; Wysokinski et al. 2015). Contrary to Horsdal et al. (2017), we were able to confirm a correlation between raised CRP levels and the white blood cell count, as documented in an earlier study (Tsai et al. 2014). However, we found only nominal but no significantly elevated CRP in the smokers vs. non-smokers in our study, in previous studies smoking significantly influenced CRP levels (Bai et al. 2015; Huang et al. 2013).

Although we could find an association between CRP concentration and mood episode, the directionality of this association cannot be positively inferred. Thus, the links between inflammation and this psychiatric disorder remain unclear and may be bi-directional. Further studies should investigate the relationship between CRP concentration and the progression of $\mathrm{BD}$, and $\mathrm{BD}$ 's potential role as an epiphenomenon of low-grade inflammation. Another explanation might be that increased CRP is due to activation of the stress axis in manic episodes because of the general increase in activity (psychomotor activity, lack of sleep, etc.). Additionally, we found a significant correlation of increased CRP levels with longer duration of the illness which could be interpreted as a sign of neuronal progression of the course of BD over the life span.

Regarding the question if CRP levels could be used as biomarker for early detection of emerging episodes in bipolar disorder or a prognostic biomarker for the course of the disorder of the life span including the development of somatic comorbidities, there are several issues that need to be addressed in future studies. The CRP level differences in the manic patients compared to the euthymic as well in our study as in previous studies are very small even if they are significantly different (Dargél et al. 2015; Uyanik et al. 2015). Therefore it is difficult to define a cut-off CRP level that could be used as an early detection for emerging manic episodes in the individual patient as well as use this as a prognostic marker for a more severe course or development of comorbid somatic diseases. It might prove more fruitful to develop composite-biomarkers for personalized early detection or prognosis by the integration of CRP and potentially other protein markers and genetic, imaging and neuropsychological data. However, to define inflammatory subgroups that might benefit from add-on inflammatory therapeutics might be possible using only slightly elevated CRP levels (Müller 2019; Soczynska et al. 2009).

In our study, there were hints that there are differences between the rs1205 SNP genotypes in our sample of bipolar patients regarding CRP levels. In a recent study investigating late life depression, female rs1205 TT carriers displayed significantly more depressed symptoms but had lower CRP levels than the other genotypes, while the AA carriers of female rs 1417938 were associated with a decreased risk of depression and had slightly elevated CRP levels (Ancelin et al. 2015). In contrast to our findings, a lower concentration of CRP was reported in men with greater odds of having clinically significant depression, but only in patients with the rs1205 minor AA genotype (Almeida et al. 2009). Similarly, the major allele CC of the rs1205 SNP was strongly associated with adolescent emotional problems and metabolic syndrome (Gaysina et al. 2011).

Minor rs1205 allele (TT) carriers, who showed in our study featuring significantly increased CRP levels, might also be at elevated risk for somatic disorders, especially including cardiovascular and metabolic diseases. Homozygous variant-type (TT) carriers of rs1205 had a threefold increased risk for heart valve reoperation and elevated CRP levels compared to ancestral allele carriers (Lee et al. 2016; Wypasek et al. 2015). Peric and collaborators also reported a trend toward higher maximum transvalvular gradient in carriers of $\mathrm{T}$ alleles in the rs 1205 $\mathrm{SNP}$, suggesting that the $\mathrm{T}$ allele could be a potential marker concerning severe and heavily calcified aortic stenosis (Peric et al. 2013). The susceptibility and severity of community-acquired pneumonia was additionally associated with the frequency of the CRP rs1205 TT genotype (Chou et al. 2016). In the future, follow-up studies would be of high interest to investigate if those BD patients of our sample with CRP risk variants and/or elevated CRP might be at an increased risk for cardiovascular disease.

The remarkable overlap between psycho-immunoendocrinologic mechanisms in BD and cardiometabolic illnesses, as well as other chronic inflammatory diseases, may be due to common genetic variants. It is of note that the rare recessive genotype rs1800947 CC of the CRP gene was recently found to have a significant influence on CRP concentration, mortality and depressive symptoms in chronic heart failure patients; the highest risk CC carriers had the highest hs-CRP levels (Kittel-Schneider et al. 2018). In comparison, our study revealed a trend of decreased CRP levels for rs1800947 CC carriers in $\mathrm{BD}$ patients which is in line with previous findings in the Health 2000 Study (Kettunen et al. 2011) as well as in other previous studies (Carlson et al. 2005; Miller et al. 2005; Zee and Ridker 2002). The reason for the contrasting results is unclear and indicated that genetic influences might lead to differential effects in different disorders. 


\section{Conclusions}

In summary, we could add to the evidence that a part of the variance of CRP expression in serum could be explained by functional variants in the CRP gene. However, the direction and effect of those genetic variants seem to vary in different somatic and psychiatric disorders, as well as in the healthy general population. However, the differences between CRP levels between $\mathrm{BD}$ patients in a manic episode vs. depressed and euthymic patients were much more pronounced than the genotype effect. Further studies are therefore needed to confirm these current findings, and to determine whether CRP might be indeed more useful as an early detection or prognostic marker in BD or at least used as a part of a composite-biomarker, or might be suitable as a biomarker for distinguishing inflammatory subgroups.

\section{Significant outcomes}

CRP protein levels were significantly increased in bipolar manic patients.

BMI, age and leukocyte levels were positively correlated with CRP protein levels.

Duration of illness was positively correlated with CRP protein levels.

\section{Strengths and limitations}

The results of our study have some limitations. Firstly, the peripheral CRP level within the blood may also be influenced by further external factors which we did not take into account. Not only may the covariates considered by the present study (such as smoking or body mass index) play a role, but other parameters such as physical activity, an unhealthy lifestyle or stress may also influence CRP concentration. We were unable to include these other possible covariates in this study. Secondly, even though we excluded patients from the study who demonstrably suffered from current infections or carcinomas, it is possible that undiagnosed illnesses may have affected CRP levels. Thirdly, longitudinal data from different timepoints would have been more informative in the search for trait- or state biomarkers and inflammatory subtypes. Finally, the validity of the genetic results is limited by the relatively low number of patients.

The strength of the study is that we investigated a naturalistic sample of bipolar patients in all episodes and we could take several variables that might influence CRP levels into account because the information was available. Furthermore, this sample consisted of a relatively homogenous origin so that influences on CRP levels and differences in CRP genetic variants due to the origin of the patients are reduced.

\section{Supplementary information}

Supplementary information accompanies this paper at https://doi. org/10.1186/s40345-019-0162-z.

Additional file 1: Table S1. Distribution of genotypes of all tested SNPS.

Additional file 2: Table S2. a. Distribution of rs2808630 genotypes with regard to current episode. b. Distribution of rs 1417938 genotypes with regard to current episode. c. Distribution of rs1205 genotypes with regard to current episode. d Distribution of rs 1800947 genotypes with regard to current episode.

\section{Abbreviations}

BD: bipolar disorder; CRP: C-reactive protein; SNPs: single nucleotide polymorphisms; MDD: major depressive disorder; BMI: body mass index; MDRD: Modification of Diet in Renal Disease; MS: mood stabilizer; Li: lithium; HPA axis: hypothalamus-pituitary-adrenal axis; KASP: Competitive Allele Specific Polymerase Chain Reaction; EDTA: ethylenediaminetetraacetic acid; FRET: fluorescence resonance energy transfer; FAM: frequency- and amplitude modulation; HEX: hexachlorocyclopentadiene.

\section{Acknowledgements}

We thank Theresia Töpner for the technical support in the genotyping and the patients for participating in this study.

\section{Authors' contributions}

AKE, JV, SKS acquired and analyzed the data and drafted the article. RMcN and AR interpreted the data and revised the draft. AR and SKS contributed equally. All authors read and approved the final manuscript.

\section{Funding}

This research did not receive any specific grant from funding agencies in the public, commercial, or not-for-profit sectors. RMcN is funded by the DAAD, Grant No 91690211.

This publication was funded by the German Research Foundation (DFG) and the University of Wuerzburg in the funding programme Open Access Publishing.

\section{Availability of data and materials}

Data are available on request.

\section{Ethics approval and consent to participate}

Written informed consent was provided by all participants before study evaluation. All procedures contributing to this work comply with the ethical standards of the relevant national and institutional committees on human experimentation and with the Declaration of Helsinki principles (Seoul, October 2008). The ethics committee of the University of Würzburg approved the study.

Consent for publication

All authors contributed to and approved the final manuscript and gave their consent for publication.

\section{Competing interests}

The authors declare that they have no competing interests.

\section{Author details}

${ }^{1}$ Department of Psychiatry, Psychosomatic Medicine and Psychotherapy, University Hospital Frankfurt, Goethe University, Frankfurt Am Main, Germany. ${ }^{2}$ Department of Psychiatry, Psychosomatic Medicine and Psychotherapy, University Hospital, University of Würzburg, Margarete-Höppel-Platz 1, 97080 Würzburg, Germany.

Received: 11 July 2019 Accepted: 18 October 2019

Published online: 02 December 2019 


\section{References}

Almeida OP, Norman PE, Allcock R, van Bockxmeer F, Hankey GJ, Jamrozik K, Flicker L. Polymorphisms of the CRP gene inhibit inflammatory response and increase susceptibility to depression: the Health in Men Study. Int J Epidemiol. 2009;38:1049-59. https://doi.org/10.1093/ije/dyp199.

Ancelin M-L, Farré A, Carrière I, Ritchie K, Chaudieu I, Ryan J. C-reactive protein gene variants: independent association with late-life depression and circulating protein levels. Transl Psychiatry. 2015;5:e499. https://doi. org/10.1038/tp.2014.145.

Avramopoulos D, Pearce BD, McGrath J, Wolyniec P, Wang R, Eckart N, Hatzimanolis A, Goes FS, Nestadt G, Mulle J, et al. Infection and inflammation in schizophrenia and bipolar disorder: a genome wide study for interactions with genetic variation. PLoS ONE. 2015;10:e0116696. https://doi. org/10.1371/journal.pone.0116696.

Bai Y-M, Su T-P, Tsai S-J, Wen-Fei C, Li C-T, Pei-Chi T, Mu-Hong C. Comparison of inflammatory cytokine levels among type I/type II and manic/hypomanic/euthymic/depressive states of bipolar disorder. J Affect Disord. 2014;166:187-92. https://doi.org/10.1016/j.jad.2014.05.009.

Bai Y-M, Su T-P, Li C-T, Tsai S-J, Chen M-H, Tu P-C, Chiou W-F. Comparison of pro-inflammatory cytokines among patients with bipolar disorder and unipolar depression and normal controls. Bipolar Disord. 2015;17:269-77. https://doi.org/10.1111/bdi.12259.

Balukova SM, Haarman BCM, Riemersma-Van der Lek RF, Schoevers RA. Does CRP predict outcome in bipolar disorder in regular outpatient care? Int J Bipolar Disord. 2016;4:14. https://doi.org/10.1186/s40345-016-0055-3.

Becking K, Boschloo L, Vogelzangs N, Haarman BCM, Riemersma-van der Lek R, Penninx BWJH, Schoevers RA. The association between immune activation and manic symptoms in patients with a depressive disorder. Transl Psychiatry. 2013;3:e314. https://doi.org/10.1038/tp.2013.87.

Benros ME, Waltoft BL, Nordentoft M, Ostergaard SD, Eaton WW, Krogh J, Mortensen PB. Autoimmune diseases and severe infections as risk factors for mood disorders: a nationwide study. JAMA Psychiatry. 2013;70:812-20. https://doi.org/10.1001/jamapsychiatry.2013.1111.

Berk M, Williams LJ, Jacka FN, O’Neil A, Pasco JA, Moylan S, Allen NB, Stuart AL, Hayley AC, Byrne ML, et al. So depression is an inflammatory disease, but where does the inflammation come from? BMC Med. 2013;11:200. https ://doi.org/10.1186/1741-7015-11-200.

Beurel E, Jope RS. Inflammation and lithium: clues to mechanisms contributing to suicide-linked traits. Transl Psychiatry. 2014;4:e488. https://doi. org/10.1038/tp.2014.129.

Carlson CS, Aldred SF, Lee PK, Tracy RP, Schwartz SM, Rieder M, Liu K, Williams OD, Iribarren C, Lewis EC, et al. Polymorphisms within the C-reactive protein (CRP) promoter region are associated with plasma CRP levels. Am J Hum Genet. 2005;77:64-77. https://doi.org/10.1086/431366.

Chakrabarti S. Thyroid functions and bipolar affective disorder. J Thyroid Res. 2011;2011:306367. https://doi.org/10.4061/2011/306367.

Chang HH, Chen PS. C-reactive protein as a differential biomarker of bipolar versus unipolar depression: response. World J Biol Psychiatry. 2017;18:734. https://doi.org/10.1080/15622975.2016.1208845.

Chou S-C, Ko H-W, Lin Y-C. CRP/IL-6/IL-10 single-nucleotide polymorphisms correlate with the susceptibility and severity of community-aquired pneumonia. Genet Test Mol Biomarkers. 2016;20:732-40. https://doi. org/10.1089/gtmb.2016.0156.

Craddock N, Jones I. Genetics of bipolar disorder. J Med Genet. 1999;36:585-94.

Dargél AA, Godin O, Kapczinski F, Kupfer DJ, Leboyer M. C-reactive protein alterations in bipolar disorder: a meta-analysis. J Clin Psychiatry. 2015;76:142-50. https://doi.org/10.4088/JCP.14r09007.

Dickerson F, Stallings C, Origoni A, Boronow J, Yolken R. Elevated serum levels of $C$-reactive protein are associated with mania symptoms in outpatients with bipolar disorder. Prog Neuropsychopharmacol Biol Psychiatry. 2007;31:952-5. https://doi.org/10.1016/j.pnpbp.2007.02.018.

Dickerson F, Katsafanas E, Schweinfurth LAB, Savage CLG, Stallings C, Origoni A, Khushalani S, Lillehoj E, Yolken R. Immune alterations in acute bipolar depression. Acta Psychiatr Scand. 2015;132:204-10. https://doi. org/10.1111/acps.12451.

ensembl.org. Hinxton: European Molecular Biology Laboratory's European Bioinformatics Institute. http://www.ensembl.org/Homo_sapiens/Variation/ Sequence? $\mathrm{db}=$ core; $\mathrm{r}=1: 159713148-159714148 ; \mathrm{v}=\mathrm{rs} 1800947 ; \mathrm{vdb}=$ varia tion;vf=1229971. Accessed 18 Aug 2018.
Fernandes BS, Steiner J, Molendijk ML, Dodd S, Nardin P, Gonçalves C-A, Jacka F, Köhler CA, Karmakar C, Carvalho AF, et al. C-reactive protein concentrations across the mood spectrum in bipolar disorder: a systematic review and meta-analysis. Lancet Psychiatry. 2016;3:1147-56. https://doi. org/10.1016/S2215-0366(16)30370-4.

Ferrari AJ, Stockings E, Khoo J-P, Erskine HE, Degenhardt L, Vos T, Whiteford HA. The prevalence and burden of bipolar disorder: findings from the Global Burden of Disease Study 2013. Bipolar Disord. 2016;18:440-50. https://doi. org/10.1111/bdi.12423.

Flores-Alfaro E, Fernández-Tilapa G, Salazar-Martínez E, Cruz M, Illades-Aguiar $B$, Parra-Rojas I. Common variants in the CRP gene are associated with serum C-reactive protein levels and body mass index in healthy individuals in Mexico. Genet Mol Res. 2012;11:2258-67. https://doi. org/10.4238/2012.May.14.5.

Fond G, Hamdani N, Kapczinski F, Boukouaci W, Drancourt N, Dargel A, Oliveira J, Le Guen E, Marlinge E, Tamouza R, et al. Effectiveness and tolerance of anti-inflammatory drugs' add-on therapy in major mental disorders: a systematic qualitative review. Acta Psychiatr Scand. 2014;129:163-79. https://doi.org/10.1111/acps.12211.

Gaysina D, Pierce M, Richards M, Hotopf M, Kuh D, Hardy R. Association between adolescent emotional problems and metabolic syndrome: the modifying effect of C-reactive protein gene (CRP) polymorphisms. Brain Behav Immun. 2011;25:750-8. https://doi.org/10.1016/j.bbi.2011.01.019.

Gildengers AG, Chung K-H, Huang S-H, Begley A, Aizenstein HJ, Tsai S-Y. Neuroprogressive effects of lifetime illness duration in older adults with bipolar disorder. Bipolar Disord. 2014;16:617-23. https://doi.org/10.1111/ bdi.12204.

Haarman BCM, Riemersma-Van der Lek RF, Burger H, Netkova M, Drexhage RC, Bootsman F, Mesman E, Hillegers MH, Spijker AT, Hoencamp E, et al. Relationship between clinical features and inflammation-related monocyte gene expression in bipolar disorder-towards a better understanding of psychoimmunological interactions. Bipolar Disord. 2014;16:137-50. https ://doi.org/10.1111/bdi.12142.

Halder I, Marsland AL, Cheong J, Muldoon MF, Ferrell RE, Manuck SB. Polymorphisms in the CRP gene moderate an association between depressive symptoms and circulating levels of C-reactive protein. Brain Behav Immun. 2010;24:160-7. https://doi.org/10.1016/j.bbi.2009.09.014.

Hayes JF, Miles J, Walters K, King M, Osborn DPJ. A systematic review and meta-analysis of premature mortality in bipolar affective disorder. Acta Psychiatr Scand. 2015;131:417-25. https://doi.org/10.1111/acps.12408.

He C, Holme J, Anthony J. SNP genotyping: the KASP assay. Methods Mol Biol. 2014;1145:75-86. https://doi.org/10.1007/978-1-4939-0446-4_7.

Henderson P, Kennedy NA, van Limbergen JE, Cameron FL, Satsangi J, Russell RK, Wilson DC. Serum C-reactive protein and CRP genotype in pediatric inflammatory bowel disease: influence on phenotype, natural history, and response to therapy. Inflamm Bowel Dis. 2015;21:596-605. https:// doi.org/10.1097/MIB.0000000000000296.

Horsdal HT, Köhler-Forsberg O, Benros ME, Gasse C. C-reactive protein and white blood cell levels in schizophrenia, bipolar disorders and depression - associations with mortality and psychiatric outcomes: a population-based study. Eur Psychiatry. 2017;44:164-72. https://doi. org/10.1016/j.eurpsy.2017.04.012.

Hsuchou H, Kastin AJ, Mishra PK, Pan W. C-reactive protein increases BBB permeability: implications for obesity and neuroinflammation. Cell Physiol Biochem. 2012;30:1109-19. https://doi.org/10.1159/000343302.

Huang C-C, Chung C-M, Leu H-B, Lin T-H, Hung S-I, Wu T-C, Huang P-H, Lin S-J, Pan W-H, Chen J-W. Genetic variation in C-reactive protein in ethnic Chinese population in Taiwan. Eur J Clin Invest. 2013;43:449-56. https:// doi.org/10.1111/eci.12067.

Jacoby AS, Munkholm K, Vinberg M, Pedersen BK, Kessing LV. Cytokines, brainderived neurotrophic factor and C-reactive protein in bipolar I disorderresults from a prospective study. J Affect Disord. 2016;197:167-74. https ://doi.org/10.1016/j.jad.2016.03.040.

Kettunen T, Eklund C, Kähönen M, Jula A, Päivä H, Lyytikäinen L-P, Hurme M, Lehtimäki T. Polymorphism in the C-reactive protein (CRP) gene affects CRP levels in plasma and one early marker of atherosclerosis in men: the Health 2000 Survey. Scand J Clin Lab Invest. 2011;71:353-61. https://doi. org/10.3109/00365513.2011.568123.

Kittel-Schneider S, Kaspar M, Berliner D, Weber H, Deckert J, Ertl G, Störk S, Angermann C, Reif A. CRP genetic variants are associated with mortality 
and depressive symptoms in chronic heart failure patients. Brain Behav Immun. 2018;71:133-41. https://doi.org/10.1016/j.bbi.2018.04.002.

Landgraf D, McCarthy MJ, Welsh DK. Circadian clock and stress interactions in the molecular biology of psychiatric disorders. Curr Psychiatry Rep. 2014;16:483. https://doi.org/10.1007/s11920-014-0483-7.

Leboyer M, Oliveira J, Tamouza R, Groc L. Is it time for immunopsychiatry in psychotic disorders? Psychopharmacology. 2016;233:1651-60. https:// doi.org/10.1007/s00213-016-4266-1.

Lee S-Y, Chen S-L, Chang Y-H, Chen PS, Huang S-Y, Tzeng N-S, Wang Y-S, Wang L-J, Lee IH, Wang T-Y, et al. Inflammation's association with metabolic profiles before and after a twelve-week clinical trial in drug-naiive patients with bipolar II disorder. PLoS ONE. 2013;8:e66847. https://doi. org/10.1371/journal.pone.0066847.

Lee KE, Kim JH, Chung JE, Lee GY, Cho YJ, Chang BC, Gwak HS. Association of inflammatory gene polymorphisms with mechanical heart valve reoperation. Springerplus. 2016;5:937. https://doi.org/10.1186/s4006 4-016-2566-x.

Marshe VS, Pira S, Mantere O, Bosche B, Looper KJ, Herrmann N, Müller DJ, Rej S. C-reactive protein and cardiovascular risk in bipolar disorder patients: a systematic review. Prog Neuropsychopharmacol Biol Psychiatry. 2017;79:442-51. https://doi.org/10.1016/j.pnpbp.2017.07.026.

Martínez-Calatrava MJ, González-Sánchez JL, Martínez-Larrad MT, Pérez-Barba M, Serrano-Ríos M. Common haplotypes of the C-reactive protein gene and circulating leptin levels influence the interindividual variability in serum C-reactive protein levels. The Segovia study. Thromb Haemost. 2007;98:1088-95.

Midic U, Oldfield CJ, Dunker AK, Obradovic Z, Uversky VN. Unfoldomics of human genetic diseases: illustrative examples of ordered and intrinsically disordered members of the human diseasome. Protein Pept Lett. 2009;16:1533-47.

Miller SA, Dykes DD, Polesky HF. A simple salting out procedure for extracting DNA from human nucleated cells. Nucleic Acids Res. 1988;16:1215.

Miller DT, Zee RYL, Suk Danik J, Kozlowski P, Chasman DI, Lazarus R, Cook NR, Ridker PM, Kwiatkowski DJ. Association of common CRP gene variants with CRP levels and cardiovascular events. Ann Hum Genet. 2005;69:62338. https://doi.org/10.1111/j.1529-8817.2005.00210.x.

Modabbernia A, Taslimi S, Brietzke E, Ashrafi M. Cytokine alterations in bipolar disorder: a meta-analysis of 30 studies. Biol Psychiatry. 2013;74:15-25. https://doi.org/10.1016/j.biopsych.2013.01.007.

Müller N. COX-2 inhibitors, aspirin, and other potential anti-inflammatory treatments for psychiatric disorders. Front Psychiatry. 2019;10:375. https://doi. org/10.3389/fpsyt.2019.00375.

Muneer A. Bipolar disorder: role of Inflammation and the development of disease biomarkers. Psychiatry Investig. 2016;13:18-33. https://doi. org/10.4306/pi.2016.13.1.18.

Munkholm K, Braüner JV, Kessing LV, Vinberg M. Cytokines in bipolar disorder vs healthy control subjects: a systematic review and meta-analysis. Psychiatr Res. 2013;47:1119-33. https://doi.org/10.1016/j.jpsychires .2013.05.018

Osby U, Brandt L, Correia N, Ekbom A, Sparén P. Excess mortality in bipolar and unipolar disorder in Sweden. Arch Gen Psychiatry. 2001;58:844-50.

Osimo EF, Cardinal RN, Jones PB, Khandaker GM. Prevalence and correlates of low-grade systemic inflammation in adult psychiatric inpatients: an electronic health record-based study. Psychoneuroendocrinology. 2018;91:226-34. https://doi.org/10.1016/j.psyneuen.2018.02.031.

Pankow JS, Folsom AR, Cushman M, Borecki IB, Hopkins PN, Eckfeldt JH, Tracy RP. Familial and genetic determinants of systemic markers of inflammation: the NHLBI family heart study. Atherosclerosis. 2001;154:681-9.

Peric D, Potaczek D, Wypasek E, Undas A. Association of the $+1846 \mathrm{c}>t$ (rs1205) polymorphism of the C-reactive protein gene with the severity of calcification and mean transvalvular gradient in aortic valve stenosis. Eur Heart J. 2013;34:P3914-P3914. https://doi.org/10.1093/eurheartj/ eht309.P3914.

Perrino C, Barabási A-L, Condorelli G, Davidson SM, de Windt L, Dimmeler S, Engel FB, Hausenloy DJ, Hill JA, van Laake LW, et al. Epigenomic and transcriptomic approaches in the post-genomic era: path to novel targets for diagnosis and therapy of the ischaemic heart? Position Paper of the European Society of Cardiology Working Group on Cellular Biology of the Heart. Cardiovasc Res. 2017;113:725-36. https://doi.org/10.1093/ $\mathrm{cvr} / / \mathrm{cr} \times 070$.

Pitchot W, Scantamburlo G, Ansseau M, Souery D. Le trouble bipolaire: une affection bien complexe. Rev Med Liege. 2012;67:366-73.

Prins BP, Abbasi A, Wong A, Vaez A, Nolte I, Franceschini N, Stuart PE, Guterriez Achury J, Mistry V, Bradfield JP, et al. Investigating the causal relationship of C-reactive protein with 32 complex somatic and psychiatric outcomes: a large-scale cross-consortium mendelian randomization study. PLoS Med. 2016;13:e1001976. https://doi.org/10.1371/journal.pmed.1001976.

Reiner AP, Beleza S, Franceschini N, Auer PL, Robinson JG, Kooperberg C, Peters U, Tang H. Genome-wide association and population genetic analysis of C-reactive protein in African American and Hispanic American women. Am J Hum Genet. 2012;91:502-12. https://doi.org/10.1016/j. ajhg.2012.07.023.

Rosenblat JD, McIntyre RS. Bipolar disorder and immune dysfunction: epidemiological findings, proposed pathophysiology and clinical implications. Brain Sci. 2017. https://doi.org/10.3390/brainsci7110144.

Soczynska JK, Kennedy SH, Goldstein BI, Lachowski A, Woldeyohannes HO, McIntyre RS. The effect of tumor necrosis factor antagonists on mood and mental health-associated quality of life: novel hypothesis-driven treatments for bipolar depression? Neurotoxicology. 2009;30:497-521. https://doi.org/10.1016/j.neuro.2009.03.004.

Tsai S-Y, Chung K-H, Huang S-H, Chen P-H, Lee H-C, Kuo C-J. Persistent inflammation and its relationship to leptin and insulin in phases of bipolar disorder from acute depression to full remission. Bipolar Disord. 2014;16:800-8. https://doi.org/10.1111/bdi.12240.

Uyanik V, Tuglu C, Gorgulu Y, Kunduracilar H, Uyanik MS. Assessment of cytokine levels and hs-CRP in bipolar I disorder before and after treatment. Psychiatry Res. 2015;228:386-92. https://doi.org/10.1016/j.psych res.2015.05.078

Wium-Andersen MK, Ørsted DD, Nordestgaard BG. Elevated C-reactive protein and late-onset bipolar disorder in 78809 individuals from the general population. Br J Psychiatry. 2016;208:138-45. https://doi.org/10.1192/bjp. bp.114.150870.

Wypasek E, Potaczek DP, Undas A. Association of the C-reactive protein gene (CRP) rs1205 C>T polymorphism with aortic valve calcification in patients with aortic stenosis. Int J Mol Sci. 2015;16:23745-59. https://doi. org/10.3390/ijms161023745.

Wysokiński A, Margulska A, Strzelecki D, Kłoszewska I. Levels of C-reactive protein (CRP) in patients with schizophrenia, unipolar depression and bipolar disorder. Nord J Psychiatry. 2015;69:346-53. https://doi. org/10.3109/08039488.2014.984755.

Zee RYL, Ridker PM. Polymorphism in the human C-reactive protein (CRP) gene, plasma concentrations of CRP, and the risk of future arterial thrombosis. Atherosclerosis. 2002;162:217-9.

\section{Publisher's Note}

Springer Nature remains neutral with regard to jurisdictional claims in published maps and institutional affiliations. 